\title{
The Quality of Written Prescriptions Received at Dental Laboratories in Tabriz, Iran
}

\author{
Roodabeh Koodaryan ${ }^{1} \&$ Ali Hafezeqoran ${ }^{1}$ \\ ${ }^{1}$ Department of Prosthodontics, School of Dentistry, Tabriz University of Medical Sciences, Tabriz, Iran \\ Correspondence: Ali Hafezeqoran, Department of Prosthodontics, School of Dentistry, Tabriz University of \\ Medical Sciences, Tabriz, Iran. Tel: 98-41-3335-5965. E-mail: hafezeqoran@gmail.com
}

Received: April 2, 2016 Accepted: April 23, 2016 Online Published: May 6, 2016

doi:10.5539/gjhs.v8n12p266

URL: http://dx.doi.org/10.5539/gjhs.v8n12p266

\begin{abstract}
Aim: This study was aimed at evaluating the quality of written prescriptions for fixed and removable prosthesis in Tabriz, northwest Iran.

Methods: To assess the quality of written prescriptions for fixed and removable partial dentures, a total of 600 questionnaires were distributed among 15 licensed dental laboratories receiving both fixed and removable prosthesis projects. The technicians were instructed to complete the questionnaires for all the received projects of fixed and removable partial prostheses and the responses were evaluated.

Results: Only $9.3 \%$ of prescriptions had clearly mentioned the status of disinfection. The patient's demographic data (age and sex) was noted in $41.3 \%$ of written prescription. Information about the shade, ceramic veneering area, and margin design of fixed partial dentures were determined in $82.6 \%, 16.3 \%$, and $13.3 \%$ of cases, respectively. The number of pontics was mentioned in $41 \%$ and pontic design in $11 \%$ of written prescriptions. For removable partial prostheses, the clasp type and position and connector design were specified in $47.7 \%$ and $30.7 \%$ of cases, respectively. However, artificial tooth molds were only mentioned in $27.3 \%$ of prescriptions.
\end{abstract}

Conclusion: Unfortunately, written prescriptions were mostly incomplete which may adversely affect the quality of prosthetic treatment.

Keywords: dental prosthesis, prescriptions, quality of health care

\section{Introduction}

Effective cooperation between dentist and dental technician is essential to provide treatment of appropriate quality (Henders, 1966; Lynch, McConnell, \& Allen, 2005). When designing the prosthesis, the dentist must consider mechanical and biological factors and provide the technician with a clearly written prescription containing details of the prosthesis design. Inadequate communication leads to low quality prosthesis which might cause inevitable tissue damage. Thereby, well-written prescriptions must necessarily accompany the items delivered to the laboratories. Written prescription is also considered a document for both dentist and technician who highlights their responsibility and hence is ethically crucial to the dentist-technician relationship.

The problem of inadequate communication was first highlighted over 30 years ago in England, Sweden, Canada, South Africa, and America and published literatures proved it in both fixed and removable prostheses. According to these studies More than $55 \%$ of cases lacked information on patient's age and sex, shape and shade of the denture, visibility of denture flange, major connector design, and disinfection of the items (Allen, 2003; Barsby, 1979; Basker \& Davenport, 1978; Lynch, 2003; Schwarz \& Barsby, 1980; Vult von Steyern, Widolf-Kroon, Nilner, \& Basker, 1995; Wolfaardt, Tan, \& Basker, 1996). Lack of essential information in the laboratory request forms result in the technician having to contact the dentist to obtain the details about desired design. However, not all technicians follow this step. Failures in communication between dental office and laboratory lead to a poorly designed prosthesis, jeopardize the success of treatment, and cause tissue damage (Aslam \& Ahmed, 2015; Berry, Nesbit, Saberi, \& Petridis, 2014a, 2014b; Dickie, Shearer, \& Ricketts, 2014). Moreover, contaminated items or inadequate disinfection of casts or impressions can facilitate the spread of infectious agents and is considered a major threat to the health of treatment team (Abichandani \& Nadiger, 2013; Begum, Ahmed, Dithi, Islam, 2013; Alshiddi \& Prosthodontics, 2014; Berry et al., 2014a).

Besides non-registered dental laboratories, there are many licensed laboratories to which thousands of items are 
referred daily. Thus, inadequate prescriptions are potential to cause major problems. No previous single study has examined the quality of laboratory prescriptions in Tabriz; thus, the purpose of this study was to assess the quality of written prescriptions for fixed and removable partial dentures delivered to laboratories.

\section{Methods}

This cross-sectional study was approved by University of Medical Science research ethic board. A paper based form was utilized for the administration of the survey. Three hundred questionnaires for metal-ceramic fixed partial dentures and the same number for removable partial dentures were distributed to 15 cooperative licensed dental laboratories that fabricated both fixed and removable prostheses (Figures 1,2). Explanations for each of the items were provided in a separate paper so that respondents had a consistent definition of each strategy. The technicians were instructed to complete the questionnaires for all the received projects of fixed and removable partial prostheses upon initial submission.

Information was sought regarding the disinfection status of the received items and patient's demographic data (age and sex). For metal-ceramic fixed partial dentures, the prescriptions contained important information about the shade, ceramic veneering area, margin design, number and design of pontics. For removable partial dentures, information about rests preparation, clasp type, connector design, and shape and shade of denture teeth was gathered. Also, participating technicians were instructed to categorize the written prescriptions into four groups, as follows:

Clear: The prosthesis treatment is clearly designed and adequately explained.

Guide: Some parts of the design are left to the technician.

Poor: The major parts of the design are left to the technician.

None: The written prescription contains any guiding information.

If the prescription was classified as Poor or None, whether the technician would contact the dentist to get more information had to be specified.

Data obtained from questionnaires were entered into SPSS software, version 17. Descriptive statistics were computed and expressed as percentage. 
Please confirm what information is present on the lab request form following the submission of each project of fixed partial dentures.

1. Have the items been disinfected by the dentist?
A. Yes (mentioned in the written instruction)
B. No (mentioned in the written instruction)
C. No (not mentioned but blood and debris are visible)
D. Not clear (not mentioned and cannot predict)

2. The following patient's general information is provided:
A. Gender and age
B. Only gender
C. Only age
D. Neither of them

3. Has the dentist specified information on shade selection?
A. Yes
B. No

4. Is the ceramic veneering area specified?
A. Yes
B. No

5. Is margin design specified?
A. Yes
B. No

6. Has the dentist specified the number of pontics?
A. Yes
B. No

7. Is the pontic design specified?
A. Yes
B. No

8. What is the appropriate statement about the written instruction?
A. It is clear and adequately explains the designed fixed restoration
B. It is a guide but some of the design is devolved to the technician
C. It is poor and most of the design is devolved to the technician
D. No guiding information is written

9. If $\mathrm{C}$ or $\mathrm{D}$ is chosen in Question 8, will you contact the dentist for further information?
A. Yes
B. No

Figure 1. Data sheet collection for fixed partial denture (English translation of the original questionnaire) 
Please confirm what information is present on the lab request following the submission of each project of removable partial dentures.

1. Have the impressions or casts been disinfected by the dentist?
A. Yes (documented in the written instruction)
B. No (documented in the written instruction)
C. No (undocumented but blood and debris are visible)
D. Not clear (undocumented and cannot predict)

2. The following patient's general information is provided:
A. Gender and age
B. Only gender
C. Only age
D. Neither of them

3. Have the abutment teeth been prepared properly?
A. Yes
B. Not well on occlusal surfaces
C. Not well on axial surfaces
D. Not well on neither occlusal nor axial surfaces

4. Has the dentist specified the design of connectors?
A. Yes
B. No

5. Is the type and position of clasps specified?
A. Yes
B. No

6. Is the design of denture teeth specified?
A. Yes
B. No

7. What is the appropriate statement about the written instruction?

A. It is clear and adequately explains the designed fixed restoration

B. It is a guide but some of the design is devolved to the technician

C. It is poor and most of the design is devolved to the technician

D. No guiding information is written

8. If C or D is chosen in Question 7, will you contact the dentist for further information?
A. Yes
B. No

Figure 2. Data sheet collection for removable partial denture (English translation of the original questionnaire)

\section{Results}

A total of 300 questionnaires for fixed partial dentures and 300 for removable partial dentures were completed and collected. $41.3 \%$ of written prescriptions included both age and sex; $41.1 \%$ mentioned only the sex ( $\mathrm{n}=247)$, and $5.8 \%$ just specified the age $(n=35) .11 .6 \%$ of written prescriptions $(n=70)$ provided no demographic characteristics of patients.

Delivered items were disinfected in $8.3 \%$ of the cases $(n=50)$; whereas, only $1 \%$ of prescriptions claimed that items were not disinfected $(n=6)$. In $90.6 \%$, technician had to guess the disinfection status by the appearance of the impressions and casts $(\mathrm{n}=544)$, which was not possible in the majority of cases $(73.1 \%)$ (Figure 3 ). 


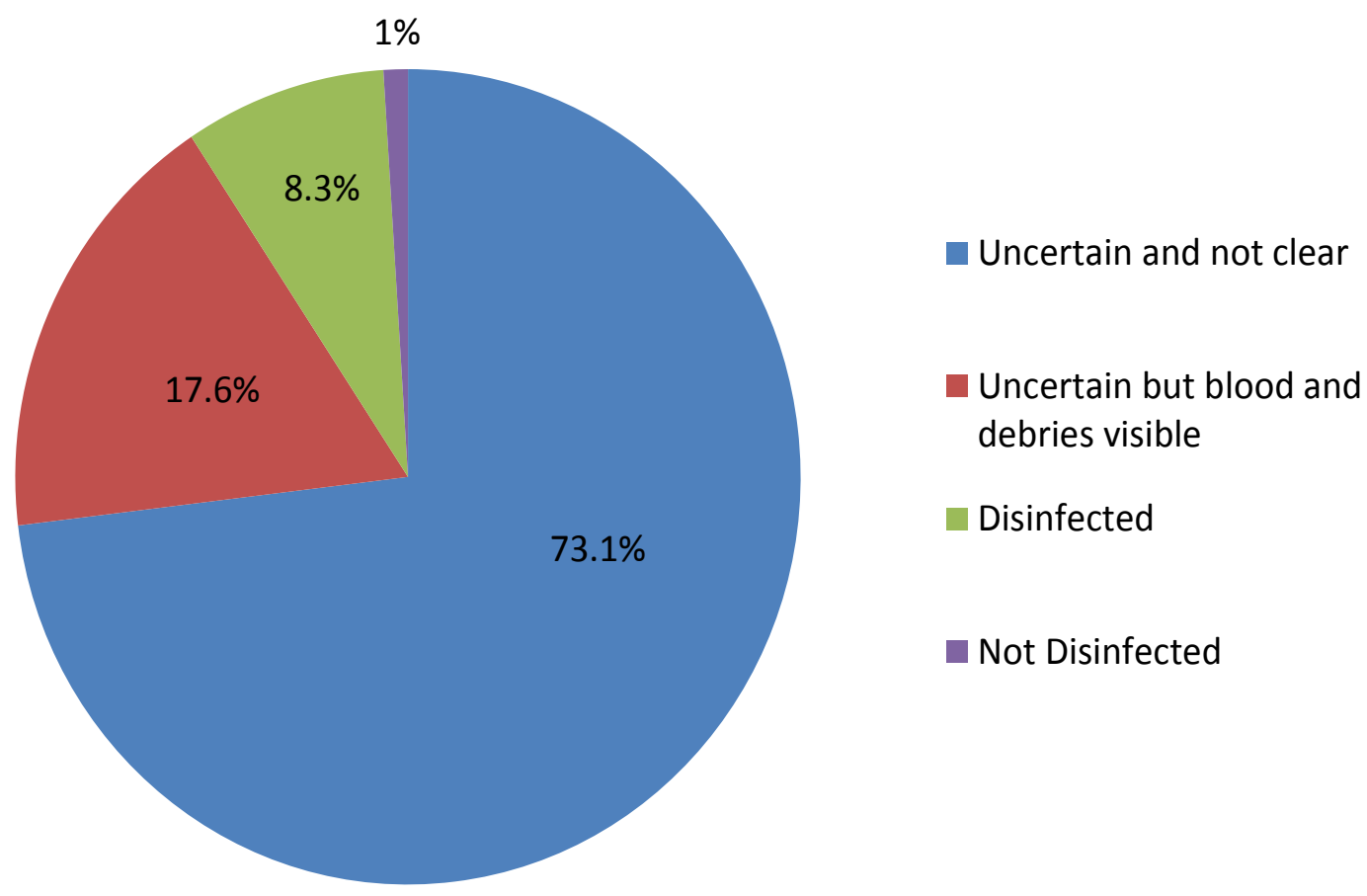

Figure 3. The disinfection status

Details of requested information for fixed partial dentures are presented in Figure 4. 82.6\% $(\mathrm{n}=248)$ of written prescriptions clarified information on tooth shade. Margin design was mentioned in $13.3 \%$ of them $(n=40)$. The number of pontics and pontic design were specified in 123 (41\%) and 33 cases (11\%), respectively.

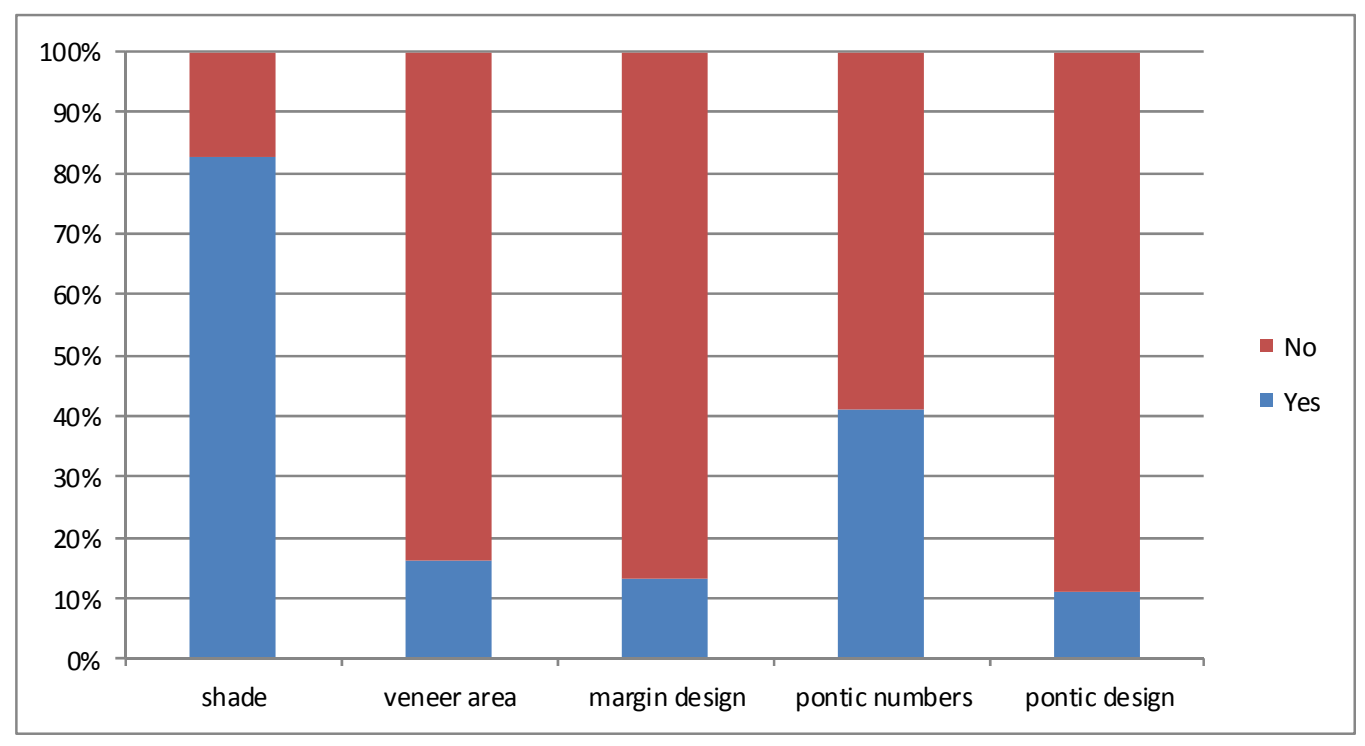

Figure 4. Information for fixed partial dentures

Information about abutment preparation, clasp design, connector design, and removable partial denture design are presented in Figure 5. Type and position of clasps were mentioned in $47.7 \%$ of cases $(n=143)$, and connector design was noted in $30.7 \%$ of written prescriptions $(n=92)$. A smaller percentage $(27.3 \%)$ of prescriptions provided information required by technician to fabricate a removable partial denture $(\mathrm{n}=82)$. 


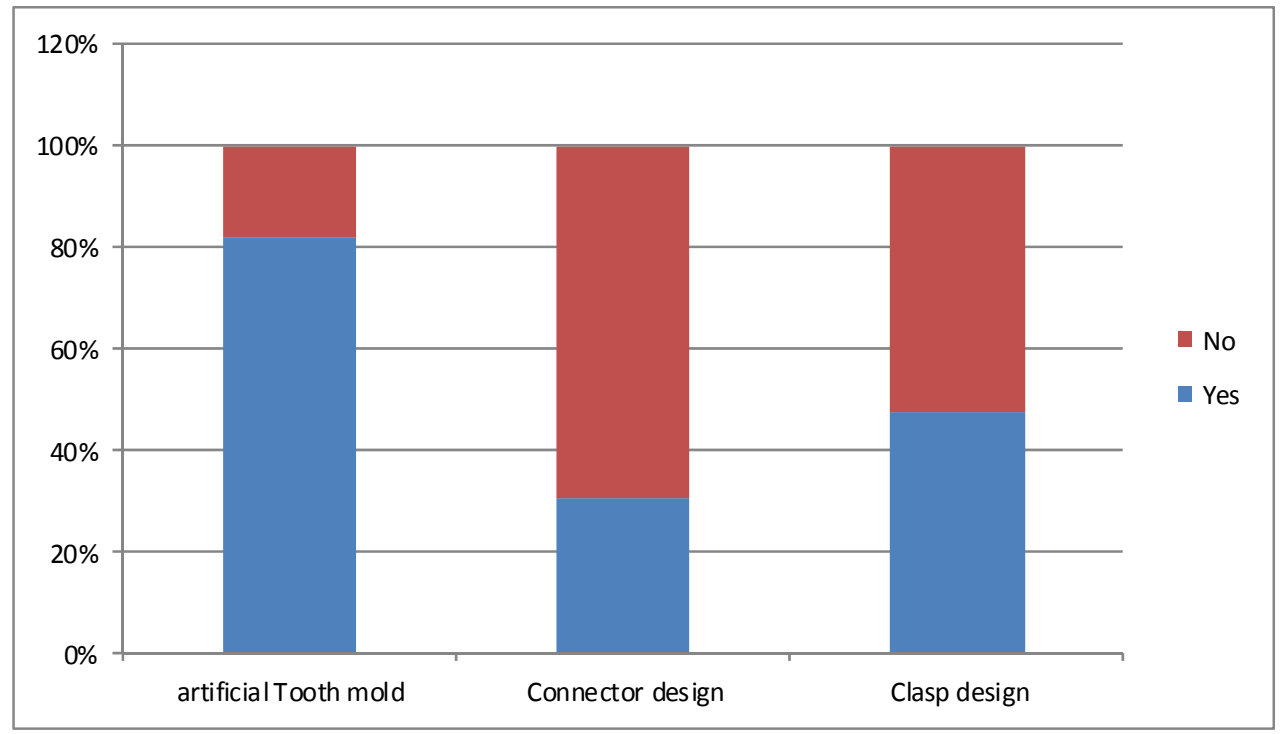

Figure 5. Information for removable partial dentures

The percentage of poorly written prescriptions for removable partial dentures preponderates over fixed partial dentures (Figure 6). It may indicate that the majority of dentists are less skilled at designing removable partial dentures. Although a high percentage of poorly prescribed instructions were seen, rarely did the technicians volunteer to contact the dentist for further information. Nearly half of prescriptions $(48.3 \%, \mathrm{n}=145)$ for fixed partial dentures were classified as Poor and None; nonetheless, in only $33.1 \%$ of cases, the technician would contact the dentist $(\mathrm{n}=48)$. Likewise, $56.6 \%(\mathrm{n}=170)$ of prescriptions for removable partial dentures were classified as Poor and None; however, $24.7 \%$ of technicians $(n=42)$ contacted the dentist for further explanations.

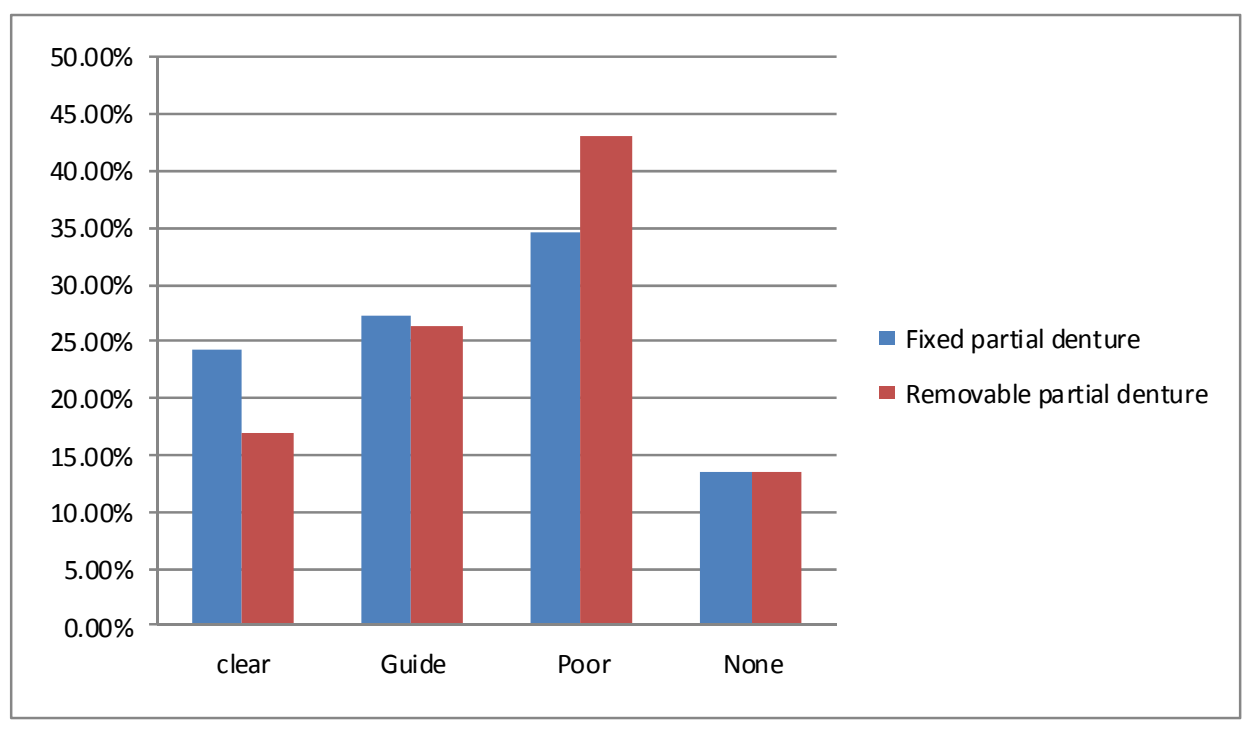

Figure 6. The opinion of the technicians about the prescriptions

\section{Discussion}

This study revealed some aspects of communication between clinician and dental technician in Tabriz. Among the delivered items, metal-ceramic fixed partial dentures and removable partial dentures were included in the study due to their more frequent application. With respect to the findings, a greater percentage of prescriptions were incomplete and the laboratory technicians mostly refused to contact clinicians for clarifications of unclear 
requests. This is similar to those observed in most developed countries.

The problem of inadequate communication between dentists and dental technicians are still observed, even though it was first highlighted approximately thirty years ago (Al-AlSheikh, 2012; Alshiddi \& Prosthodontics, 2014; Aslam \& Ahmed, 2015; Basker \& Davenport, 1978; Wolfaardt et al., 1996). Inadequate instruction devolves the treatment planning to the technician who does not have the necessary knowledge of biological and mechanical principles in designing the definitive prostheses. Thus, dental technician can barely design the appropriate treatment for the patient. When the final impression is delivered to the laboratory without sufficient information about prosthesis design, the technician would intend to fabricate prosthesis without accessing essential clinical information such as the health status of periodontal tissues; subsequently, unnecessary and unjustified tissue damage would likely to occur. So the prostheses must be designed by the dentist.

Patient's demographic data including name, sex, and age were not clarified for the lab in most cases. Although this information does not influence the design of the prostheses, they should not be ignored because they help the technician choose the shade and mold of denture teeth, determine the gingival line, as well as simulate the gingival recession in the elderly.

Blood and debris were observable on $17.5 \%$ of the items. Moreover, disinfection status of the items was mentioned in only $9.3 \%$ of the cases $(8.3 \%$ positive, $1 \%$ negative). These results were similar to those of other studies (Al-AlSheikh, 2012; Radhi, Lynch, \& Hannigan, 2007; Scully, Moles, \& Fiske, 2007). Al-Kheraif evaluated infection control in Riyadh, Saudi Arabia, and reported that the impressions referred to $9.4 \%$ of laboratories were not disinfected (Al-kheraif, 2008) and laboratories did not even receive any feedback on disinfecting process in $90.6 \%$ of the cases. Imperfect disinfection of casts or impressions facilitates the transmission of infectious agents in healthcare settings and jeopardizes the health of prosthetic treatment team particularly dental technicians who touch the items without wearing gloves (Al-kheraif, 2008; Scully et al., 2007). Since there is no specific solution to this problem, dentist is responsible for disinfecting the items delivered to the laboratory. Although infection control and disinfecting methods are widely taught in dental schools and textbooks, dentists refuse to do it for unknown reasons. The causes of negligence should be seriously considered since it can threaten the health of people involved in the procedure for fabrication of prostheses. In order to solve this problem, Sui (Sui, X. Wu, S. Wu, Gao, \& Li, 2014) suggested that dental laboratories design request forms with specific sections containing information about disinfection. The structured form automatically reminds the dentist to clean and disinfect the items prior to sending them.

In fixed partial dentures, information about metal substructure design which included the ceramic veneering area and margin design yielded frustrating results. Explanations for each of these categories were provided in respectively $16.3 \%$ and $13.3 \%$ of written prescriptions. A metal framework is planned and designed by clinicians according to professional knowledge as well as clinical findings and balance between esthetics and function (Al-AlSheikh, 2012). When metal occlusal contacts are preferred, it must be clearly explained in the written prescription so that dental technician does not cover the area with ceramic for superior aesthetics. The design of finish line is determined with respect to its geometry and consequently the margin of the restoration matches the finish line prepared on the abutment tooth (Berry et al., 2014a; Dickie et al., 2014; Lynch et al., 2005). So, the technician must necessarily be informed about tooth preparation design and margin, otherwise he would routinely use metal ceramic margin which leads to over-contour and ultimately results in gingivitis (Al-AlSheikh, 2012).

The number of pontics being replaced was mentioned in $41 \%$ of the cases; while, pontic design was only noted in $1 \%$ of prescriptions. Financial considerations are the reason why number of pontics receives more attention (Al-AlSheikh, 2012; Sui et al., 2014). The majority of laboratories charge a definite fee per pontic; thus unspecified number of pontics results in an additional cost. The pontic design is more important than other factors and is determined according to the patient's aesthetic expectations and oral hygiene (Sui et al., 2014). Most laboratories prefer ridge-lap pontics in which the aesthetic goals are more simply achieved. However, this design is not suggested because of hygienic considerations.

The preparation of abutment teeth, connector design, and choosing the type of artificial denture teeth were the main problems concerning removable partial dentures. Selective preparation of tooth surfaces prior to the fabrication of the removable partial prostheses is undoubtedly important and largely emphasized within dental school curriculum. If these principles are not followed in fabricating partial prostheses, the health of the masticatory system and periodontal tissue will be threatened.

This study revealed that in $35 \%$ of the cases, the abutment teeth were not adequately reduced on either the occlusal or the axial surfaces; whereas, $55.3 \%$ had insufficient reduction on both dimensions. In such cases, the 
guiding plane, rest seat or other components of the prosthesis would have inappropriate thickness leading to fracture or deformation of the removable partial denture components. Unfortunately, the connector design was not noted in $69.3 \%$ of the cases. Dentists are professionally responsible for determining the connector design. Stripe or bar major connectors are frequently prescribed for the maintenance of good oral and periodontal health. However for patients with underlying periodontal problems, palatal or lingual plates are preferred due to the stabilizing effects of the plates and the possibility of adding artificial teeth to the framework (Allen, 2003; Avrampou et al., 2012; Carneiro, 2006; Radhi et al., 2007).

Selecting the artificial teeth was quiet commonly disregarded in written prescriptions. It was left to the technician in almost $72.7 \%$ of the cases which may affect the ultimate functional and aesthetic outcomes. The results of this study are generally in line with surveys conducted in various regions of the world (Al-AlSheikh, 2012; Aslam \& Ahmed, 2015; Avrampou et al., 2012; Berry et al., 2014b; Cotmore, Mingledorf, Pomerantz, \& Grasso, 1983; Dickie et al., 2014; Haj-Ali, Al Quran, \& Adel, 2012; Radhi et al., 2007; Schwarz \& Barsby, 1980).

Lynch and Allen conducted various surveys on this issue and showed inadequate written instructions (Allen, 2003; Lynch et al., 2005; Lynch CD, 2003). They also evaluated the effects of financial and educational factors on the quality of removable partial dentures fabricated by general dentists and concluded that financial factors were not as influential as educational ones. Sui reported that inadequate education and lack of professional guidelines are among the major potential reasons (Sui et al., 2014). Undergraduate training rarely involves the student undertaking any fixed prosthetic laboratory procedures and as a result the dentist may fail to understand the complexities of manufacture. In spite of the undeniable importance of dental training, continuing education helps dentists to keep pace with laboratory technologies and new designs. Unfortunately, dental practitioners overlook training courses thus consequently face problems in realizing new and innovative technologies which may hamper effective writing of the prescription. Moreover, there is no professional guideline for responsibilities of clinicians and technicians. Thus, the dentist devolves a part of his responsibility to the technician who, in turn, refuses to contact the dentist for further clarification.

Designing removable partial denture is the sole responsibility of the dentist. Some developed countries have professional guidelines and mandatory policies about writing prescriptions. British Dental Association published the "Guidelines for Crown and Bridge" for British dentists to provide clear and precise details on all aspects of crowns and bridges (Shearer, 1999). Based on some state laws, written prescription must be necessarily attached to all items sent to labs in the united states (Carneiro, 2006). Using these documents can be helpful in preparing a similar mandatory professional guideline, simplifying the communication process.

In conclusion, a higher percentage of prescriptions sent to the dental laboratories were poorly written and important information about the fabrication process and disinfection status was missed. Effective cooperation between dentist and technician through a well-written prescription containing details about the design improves the prosthesis quality. It is recommended that dental curriculum educates dentist-technician communication in addition to the technical procedures. Moreover, continuous professional courses which strengthen the should be encouraged.

\section{Conclusion}

The prescriptions were mostly incomplete and information regarding the fabrication and design of prosthesis were missed. The written instruction often lacks. However, few technicians contacted the dentist to get clarification on the prosthesis design. Similar to the policies in some developed countries, preparing a mandatory professional guideline, simplifies the communication process.

\section{Competing Interests Statement}

The authors declare that there is no conflict of interests regarding the publication of this paper.

\section{References}

Abichandani, S., \& Nadiger, R. (2013). Cross-contamination in dentistry: A comprehensive overview. Chron Young Sci, 4, 51. http://dx.doi.org/10.4103/2229-5186.108807

Al-AlSheikh, H. M. (2012). Quality of communication between dentists and dental technicians for fixed and removable prosthodontics. KSUJDS, 3, 55-60. http://dx.doi.org/10.1016/j.ksujds.2012.07.002

Al-kheraif, A. A. (2008). Infection control practice in private dental laboratories in Riyadh. Saudi Dent J, 20, 163-169.

Allen, P. F. (2003). A Survey of Chrome-Cobalt RPD Design in Ireland. Int J Prosthodont, 16, 362-364. 
Alshiddi, I. F., \& Prosthodontics, D. C. D. (2014). Communication between Dental Office and Dental Laboratory: From Paper-Based To Web-Based. PODJ, 34, 555-559.

Aslam, A., \& Ahmed, B. (2015). Bridging the Gap. Quality of Communication between Prosthodontists and Lab Technicians. PODJ, 35, 148-151.

Avrampou, M., Kamposiora, P., Papavasiliou, G., Pissiotis, A., Katsoulis, J., \& Doukoudakis, A. (2012). Design of removable partial dentures: A survey of dental laboratories in Greece. Int J Prosthodont, 25, 66-9.

Barsby, M. J., \& Schwarz, W. D. (1979). A survey of the teaching of partial denture construction in dental schools in the United Kingdom. $J$ Dent, 7, 1-8. http://dx.doi.org/10.1016/0300-5712(79)90031-9

Basker, R. M., \& Davenport, J. C. (1978). A survey of partial denture design in general dental practice. J Oral Rehabil, 5, 215-222. http://dx.doi.org/10.1111/j.1365-2842.1978.tb01238.x

Begum, A., Ahmed, R., Dithi, A. B., Islam, M. S., \& Shaikh, M. H. (2013). Infection control protocol in prosthetic laboratory. $C D C J, 41,2013$. http://dx.doi.org/10.3329/cdcj.v10i2.16347

Berry, J., Nesbit, M., Saberi, S., \& Petridis, H. (2014a). Communication methods and production techniques in fixed prosthesis fabrication: A UK based survey. Part 1: Communication methods. Bdj, 217, E12-E12. http://dx.doi.org/10.1038/sj.bdj.2014.643

Berry, J., Nesbit, M., Saberi, S., \& Petridis, H. (2014b). Communication methods and production techniques in fixed prosthesis fabrication: A UK based survey. Part 2: Production techniques. Bdj, 217, E13-E13. http://dx.doi.org/10.1038/sj.bdj.2014.644

Carneiro, L. C. (2006). Specifications provided by practitioners for fabrication of removable acrylic prostheses in Tanzania. J Oral Rehabil, 33, 660-665. http://dx.doi.org/10.1111/j.1365-2842.2005.01611.x

Cotmore, J. M., Mingledorf, E. B., Pomerantz, J. M., \& Grasso, J. E. (1983). Removable partial denture survey: Clinical practice today. J Prosthet Dent, 49, 321-327. http://dx.doi.org/10.1016/0022-3913(83)90269-X

Dickie, J., Shearer, A. C., \& Ricketts, D. N. J. (2014). Audit to assess the quality of communication between operators and technicians in a fixed prosthodontic laboratory: Educational and training implications. Eur $J$ Prosthodont Restor Dent, 18, 7-14. http://dx.doi.org/10.1111/eje.12050

Haj-Ali, R., Al Quran, F., \& Adel, O. (2012). Dental Laboratory Communication Regarding Removable Dental Prosthesis Design in the UAE. $J$ of Prosthodont, 21, 425-428. http://dx.doi.org/10.1111/j.1532-849X. 2011.00842.x

Henders, D. (1966). Work Authorizations for Removable Partial Dentures. J Prosthet Dent, 16, 284-288.

Lynch, C. D. (2003). Quality of materials supplied to dental laboratories for the fabrication of cobalt chromium removable partial dentures in Ireland. Eur J Prosthodont Restor Dent, 11, 176-180.

Lynch, C. D., McConnell, R. J., \& Allen, P. F. (2005). Trends in Indirect Dentistry: 7. Communicating Design Features for Fixed and Removable Prostheses. Dental Update, 32, 502-10.

Radhi, A., Lynch, C. D., \& Hannigan, A. (2007). Quality of written communication and master impressions for fabrication of removable partial prostheses in the Kingdom of Bahrain. J Oral Rehabil, 34, 153-157. http://dx.doi.org/10.1111/j.1365-2842.2006.01685.x

Schwarz, W. D., \& Barsby, M. J. (1980). A survey of the practice of partial denture prosthetics in the United Kingdom. J Dent, 8, 95-101. http://dx.doi.org/10.1016/0300-5712(80)90023-8

Scully, C., Moles, D. R., \& Fiske, J. (2007). Infection control: A survey of UK special care dentists and dental care professionals. Prim Dent Care, 14, 40-6. http://dx.doi.org/10.1308/135576107780556815

Shearer, A. (1999). Guidelines for crown and bridge. Eur J Prosthodont Restor Dent, 7, 3-9.

Sui, L., Wu, X., Wu, S., Gao, P., \& Li, R. (2014). The Quality of Written Instructions for Dental Prostheses in China. J of Prosthodont, 23, 602-609. http://dx.doi.org/10.1111/jopr.12163

Vult von Steyern, P., Widolf-Kroon, R., Nilner, K., \& Basker, R. M. (1995). Removable partial denture design habits in general dental practice in Sweden. Swed Dent J, 19, 205-211.

Wolfaardt, J. F., Tan, H. K., \& Basker, R. M. (1996). Removable partial denture design in Alberta dental practices. J Can Dent Assoc, 62, 637-644. 


\section{Copyrights}

Copyright for this article is retained by the author(s), with first publication rights granted to the journal.

This is an open-access article distributed under the terms and conditions of the Creative Commons Attribution license (http://creativecommons.org/licenses/by/3.0/). 